\title{
Hang-out time of pulmonary valve in d-transposition of great arteries
}

\author{
J C FOURON, M Y DOUSTE-BLAZY, , G DUCHARME, N vAN DOESBURG, A DAVIGNON \\ From the Cardiology Section, Departments of Paediatrics and Paediatric Research, Sainte-Fustine Hospital and \\ University of Montreal, Quebec, Canada
}

SUMMARY Recently it has been shown that in patients with transposition of the great arteries the isometric relaxation time of the left ventricle could be negative in the presence of normal pulmonary artery pressure. In order to find an explanation for this apparently paradoxical situation, it was decided to evaluate the importance of the delay of closure of the pulmonary valve in 15 patients with transposition of the great arteries. This delay is called the hang-out time. The hang-out time was found to correlate inversely with the isometric relaxation time as well as with the pulmonary artery systolic $(\mathrm{r}=-0.70)$ and mean pressures. A weaker correlation was found between the isometric relaxation time and the time of mitral valve opening. These results show that in transposition of the great arteries with normal pulmonary artery pressure, the pulmonary valve has a prolonged hang-out time, to the extent that it frequently closes after the opening of the mitral valve, explaining the negative isometric relaxation time found in these cases. This finding may help in the non-invasive assessment of the pulmonary vascular resistance of patients with transposition of the great arteries.

In a recent publication we have shown that in transposition of the great arteries the isometric relaxation period of the left ventricle, measured non-invasively, had a strong correlation with the pulmonary artery pressure. ${ }^{1}$ The isometric relaxation time was also found to be negative in the presence of a normal pulmonary pressure, suggesting that in these circumstances the mitral valve paradoxically opens before the pulmonary valve closes. The reasons for this peculiar situation are still speculative. Early mitral opening, late pulmonary closure, or both, are obvious possibilities. The pulmonary valve is known to close sometimes after the end of ventricular ejection. This delay of closure is called the hang-out time. ${ }^{2}$ When right ventricular and pulmonary artery pressures are simultaneously recorded by high-fidelity cathetertipped micromanometers, the hang-out time can easily be measured and corresponds to the interval separating the pulmonary incisura from the right ventricular pressure tracing at the level of the incisura.

Work supported in part by the Canadian Heart Foundations, the MacDonald Stewart Fcundation, and La Fondation Justine Lacoste-Beaubien.

^ Present address: Service de Cardiologie, Hôpital Purpan, Toulouse 31000, France.

Accepted for publication 11 May 1981
This interval is influenced mainly by the capacitance of the pulmonary vascular bed. ${ }^{2}$ The purpose of the present study was to investigate whether the hang-out time of the pulmonary valve of patients with transposition of the great arteries could be prolonged to the point that late pulmonary closure would be the factor responsible for the negative isometric relaxation time observed in the presence of normal pulmonary pressure.

\section{Subjects and methods}

Echocardiograms were obtained in 15 children with transposition of the great arteries aged 1 day to 5 years. All studies were done within 48 hours of cardiac catheterisation. Patients with pulmonary stenosis were excluded from the study since in these cases other factors such as stiffness of the pulmonary leaflets could affect their time of closure. Tracings were recorded simultaneously with an electrocardiogram on a Smith Kline Ekoline 20A, coupled with a Honeywell fibreoptic recorder (model 1856). Paper speed was set at $100 \mathrm{~mm} / \mathrm{s}$, allowing measurement to the nearest $5 \mathrm{~ms}$. Aerotech $5 \mathrm{MHz}$ unfocused and 3.5 $\mathrm{MHz}$ focused transducers were used, according to the size of the patients.

The left ventricular pre-ejection period was meas- 
ured from the onset of depolarisation (beginning of the $Q$ wave on the electrocardiogram) to the opening of the pulmonary valve. The ejection time was determined by two methods: first, from opening to closure of the pulmonary valve, ${ }^{3}$ and second, by taking the point of maximal anterior movement of the left ventricular wall as the end of ejection (E point), ${ }^{4}$ with the ejection time as the difference between the interval $\mathrm{Q}-\mathrm{E}$ and the pre-ejection period. The hang-out time was calculated as the difference between the two figures. (Fig. 1). The isometric relaxation time of the left ventricle was calculated as the difference between $Q$ to mitral valve opening and $Q$ to pulmonary valve closure, as previously described. ${ }^{1}$ All measurements were done on cardiac cycles with equal preceding RR intervals. Each value represents the mean of at least five different complexes.

The relation between the hang-out time and the isometric relaxation time, as well as the pulmonary pressures, was evaluated by linear regression analysis. To appreciate the possible influence of the time of opening of the mitral valve on the isometric relaxation time, correlation between the latter and $Q$ to mitral valve opening was also studied.

\section{Results}

Echocardiographic and catheterisation data are summarised in the Table. In five cases with no angiographic signs of pulmonary stenosis, the pulmonary artery was not entered and only left ventricular systolic pressures are given. In three of them (cases 7, 13, and 14), the absence of a gradient was confirmed at surgery. Pulmonary stenosis was also ruled out at the necropsy of case 12 .

The hang-out time of the pulmonary valve was positive in nine patients (Fig. 1A) and negative in six (Fig. 1B). A strong inverse correlation was observed between isometric relaxation time and hang-out time $(\mathrm{r}=-0.88, \mathrm{p}<0.001)$ (Fig. 2). All patients with a negative isometric relaxation time had a positive hang-out time. Patients with a positive isometric
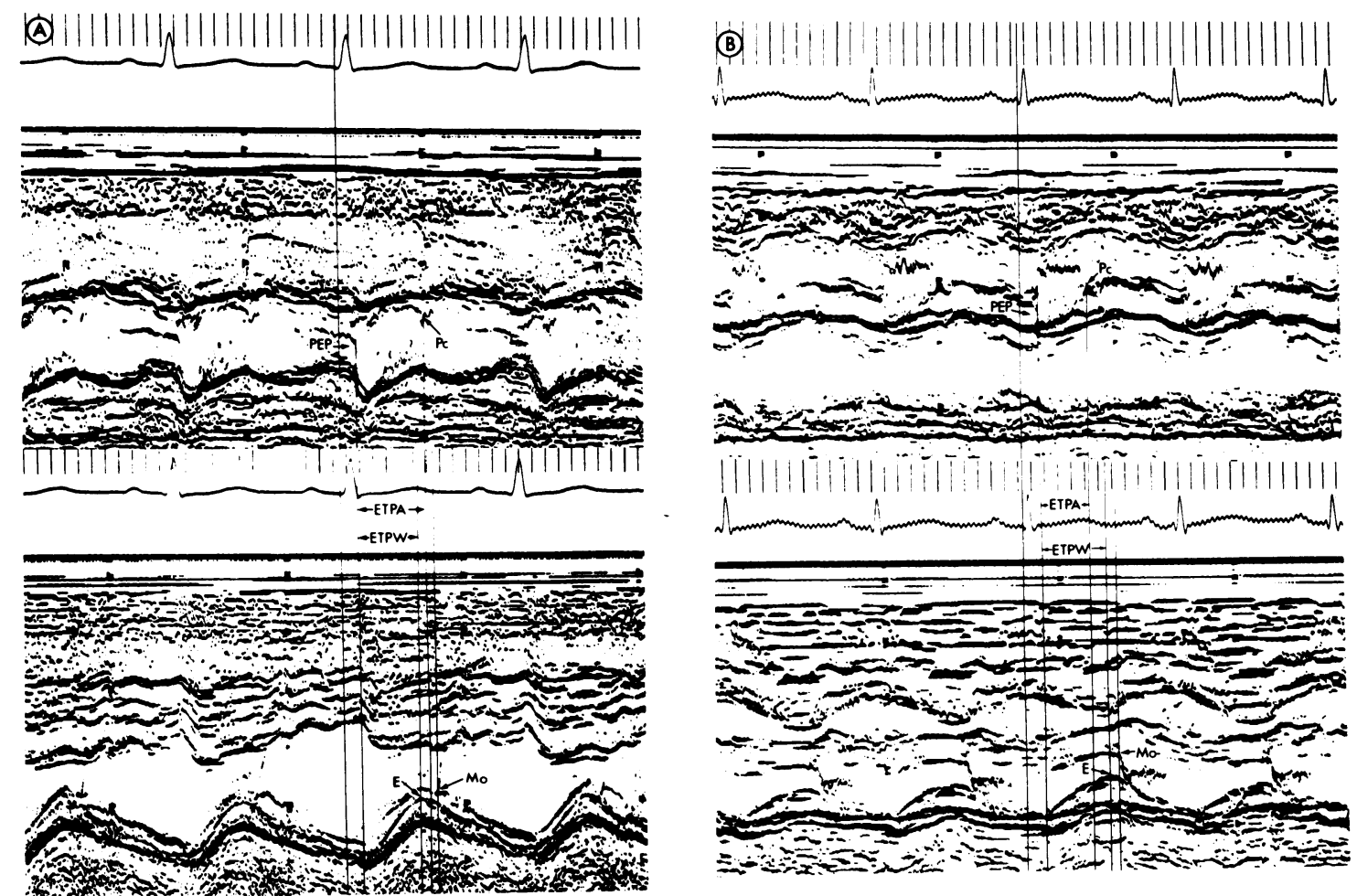

Fig. 1 Echocardiograms of pulmonary and mitral valves of two children with transposition of the great arteries demonstrating the technique used to measure the left ventricular ejection time on the pulmonary artery (ETPA) and on the posterior wall of the left ventricle $(E T P W)$. The hang-out time is measured by subtracting ETPW from ETPA. (A) Example of a positive hang-out time. (B) Example of a negative hang-out time. This child had severe pulmonary hypertension. Mo, mitral valve opening; Pc, pulmonary valve closure; PEP, pre-ejection period. 
Table Echocardiographic and haemodynamic data

\begin{tabular}{|c|c|c|c|c|c|c|c|c|}
\hline Case No. & Age & $\begin{array}{l}\text { Associated } \\
\text { lesions }\end{array}$ & $\begin{array}{l}\underset{(m s)}{E T P W} \\
(m s\end{array}$ & $\begin{array}{l}\underset{(m s)}{E T P A} \\
(m s\end{array}$ & $\begin{array}{l}H T \\
(m s)\end{array}$ & $\begin{array}{l}I R T \\
(m s)\end{array}$ & $\begin{array}{l}P A(m m H g) \\
\text { Systolic }\end{array}$ & Mean \\
\hline $\begin{array}{r}1 \\
2 \\
3 \\
4 \\
5 \\
6 \\
7 \\
8 \\
9 \\
10 \\
11 \\
12 \\
13 \\
14 \\
15\end{array}$ & $\begin{array}{c}7 \mathrm{mth} \\
16 \mathrm{mth} \\
30 \mathrm{mth} \\
2 \mathrm{~d} \\
33 \mathrm{mth} \\
2 \mathrm{y} \\
6 \mathrm{mth} \\
24 \mathrm{mth} \\
26 \mathrm{mth} \\
24 \mathrm{mth} \\
12 \mathrm{mth} \\
26 \mathrm{mth} \\
6 \mathrm{mth} \\
12 \mathrm{mth} \\
2 \mathrm{~d}\end{array}$ & VSD & $\begin{array}{l}200 \\
200 \\
215 \\
170 \\
220 \\
225 \\
225 \\
200 \\
240 \\
225 \\
240 \\
190 \\
220 \\
165 \\
210\end{array}$ & $\begin{array}{l}230 \\
215 \\
270 \\
180 \\
240 \\
250 \\
180 \\
220 \\
250 \\
210 \\
230 \\
145 \\
210 \\
225 \\
170\end{array}$ & $\begin{array}{r}30 \\
15 \\
55 \\
10 \\
20 \\
25 \\
-45 \\
20 \\
10 \\
-15 \\
-10 \\
-45 \\
-10 \\
60 \\
-40\end{array}$ & $\begin{array}{r}-30 \\
20 \\
-10 \\
10 \\
-15 \\
-15 \\
45 \\
5 \\
10 \\
40 \\
45 \\
90 \\
70 \\
-25 \\
55\end{array}$ & $\begin{array}{l}22 \\
17 \\
36 \\
45 \\
20 \\
23 \\
60 \\
36 \\
21 \\
95 \\
87 \\
82 \\
65 \\
30 \\
64\end{array}$ & $\begin{array}{r}14 \\
9 \\
15 \\
32 \\
11 \\
16 \\
\\
20 \\
16 \\
77 \\
65\end{array}$ \\
\hline
\end{tabular}

ETPW, ejection time calculated on the posterior wall of the left ventricle; ETPA, ejection time measured on the pulmonary valve; HT, hang-out time; IRT, isovolumic relaxation time; PA, pulmonary artery; VSD, ventricular septal defect.

relaxation time greater than $20 \mathrm{~ms}$. had a negative hang-out time. An inverse correlation was also found between the hang-out time and the systolic ( $r=$ $-0.70, p<0.005)$ (Fig. 3) and the mean $(r=-0.78$, $\mathrm{p}<0.005$ ) pulmonary pressures. All six patients with a negative hang-out time had a systolic pulmonary pressure higher than $60 \mathrm{mmHg}$. A positive but weaker correlation was found between the isometric relaxation time and the $Q$ to mitral valve opening interval $(\mathrm{r}=0.56, \mathrm{p}<0.05)$.

\section{Comments}

Several methods have been proposed to evaluate the left ventricular ejection time by echocardiography. The most widely used relies on the time of opening and closure of the aortic valve. ${ }^{3}$ These two points can indeed be easily identified but this method includes

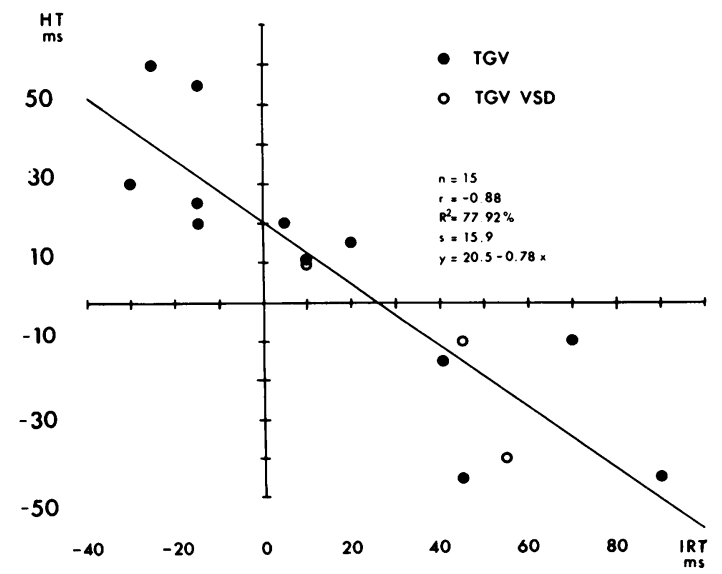

Fig. 2 Correlation between the hang-out time (HT) and the isometric relaxation time (IRT).

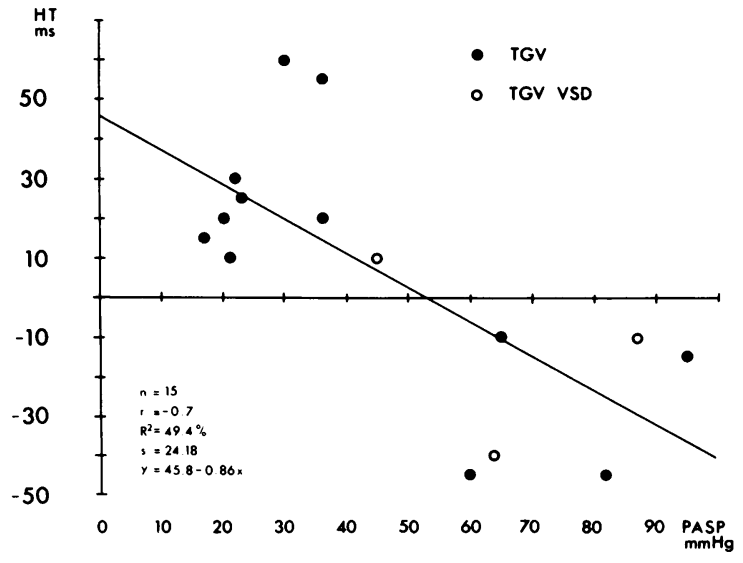

Fig. 3 Correlation between the hang-out time (HT) and the pulmonary arterial systolic pressure (PASP).

the hang-out time of the valve in the ejection time of the ventricle. While in the systemic circulation the hang-out time can be considered negligible (less than $15 \mathrm{~ms}$ ), this is, however, not the case in the normal, highly capacitant, pulmonary circulation, in which it may vary between 30 and $120 \mathrm{~ms}^{2}$ In most cases of transposition of the great arteries, vascular resistance is low and pulmonary flow increased. The hang-out time of the pulmonary valve can thus be expected to be in the high ranges. This could explain why left ventricular ejection time in transposition of the great arteries, measured from the pulmonary valve, has been found to be prolonged when pulmonary pressure is normal. ${ }^{3} 5$

Another method of measuring left ventricular ejection time, based on posterior wall systolic excursion, excludes the hang-out time. Measurements are made either from the beginning to the maximum of the sys- 
tolic forward movement of the endocardium, or from the $\mathrm{Q}$ wave to the maximum of forward movement of the posterior wall minus $50 \mathrm{~ms}^{4}$ In our study, the latter method was used, the $Q$ wave being a point easily identifiable. The standard value of $50 \mathrm{~ms}$, used as the pre-ejection period of the systemic circulation, could not be used in transposition of the great arteries where the left ventricle faces the pulmonary circulation. Therefore for each case the actual pre-ejection period was subtracted from the Q-E point. This method has been shown to overestimate left ventricular ejection time. ${ }^{4}$ The reason for this overestimation is unclear. In the present study this has probably led to an underestimation of the hang-out time and can therefore explain the negative values observed in the cases with pulmonary hypertension in which a very short hang-out time would normally be expected. ${ }^{6}$

While the absolute values found for the hang-out time in this study may be underestimated, this does not invalidate the correlations observed between this measurement and the isometric relaxation time or the pulmonary pressures. In transposition of the great arteries, with a normal pulmonary pressure, pulmonary vascular resistance is low and the hang-out time is prolonged to such a point that pulmonary closure occurs after mitral opening, explaining the negative isometric relaxation time found in most of these cases. ${ }^{1}$ Variations in the latter are also correlated, but to a lesser degree, with the timing of mitral valve opening. Indeed, in this study, the mitral valve tended to open earlier in the presence of negative isometric relaxation time and normal pulmonary pressure. One can speculate that in transposition of the great arteries when the pulmonary resistance is low, the pulmonary flow is generally increased. This leads to a higher pulmonary venous return into the left atrium which could be responsible for an earlier opening of the mitral valve.

This study confirms the validity of the isometric relaxation time of the left ventricle as an index of the pulmonary pressure in transposition of the great arteries. Measurement of the hang-out time of the $c$. pulmonary valve appears to be another and much $\underset{\overrightarrow{5}}{\overrightarrow{5}}$ quicker means of evaluating this pressure. In routine $\frac{0}{+}$ echocardiography of patients with transposition of the great arteries, a rapid assessment of pulmonary arter- $\frac{\bar{c}}{\bar{c}}$. ial pressure can indeed be made, simply by measuring $\vec{\sigma}$ the intervals $Q$ to the end of ejection and $Q$ to pulmo- $Q$ nary valve closure on two cycles with the same preced- $\%$ ing RR intervals. In the presence of low pulmonary $\vec{\circ}$ pressure the latter should always be longer than the former. This observation does not predict an absolute $\vec{\omega}$ value for the pulmonary arterial pressure, but a nega- $\frac{\partial}{\partial}$ tive hang-out time should certainly help in detecting pulmonary hypertension during the follow-up of such $\mathrm{v}$ patients.

\section{References}

1 Bourlon F, Fouron JC, Battle-Diaz J, Ducharme G, 을 Davignon A. Relation between isovolumic relaxation $\frac{\rho}{\supset}$ period of left ventricle and pulmonary artery pressure in $\vec{\imath}$ d-transposition of the great arteries. Br Heart $\mathcal{F} 1980 ; 43: \stackrel{\infty}{\infty}$ 226-31.

2 Shaver JA, O'Toole JD. The second heart sound: newer concepts. Part I: Normal and wide physiological splitting. Mod Concepts Cardiovasc Dis 1977; 46: 7-12.

3 Hirschfeld S, Meyer R, Schwartz DC, Korfhagen J, ํํㅇ Kaplan S. Measurement of right and left ventricular sys- $\frac{O}{D}$ tolic time intervals by echocardiography. Circulation 을 1975; 51: 304-9.

4 Björkhem G. Echocardiographic assessment of left ven- 3 tricular function. Eur $\mathcal{F}$ Cardiol 1977; 6: 83-98.

5 Gutgesell HP, Pinsky WW, Duff DF, Adams J, McNamara D. Left and right ventricular systolic time intervals in the newborn. Br Heart $\mathcal{F} 1979$; 42: 27-34.

6 Shaver JA, Nadolny RA, O'Toole JD, et al. Sound pressure correlates of the second heart sound: an intracardiac $\bar{\sigma}$ sound study. Circulation 1974; 49: 316-25.

Requests for reprints to Dr Jean-Claude Fouron, Sainte-Justine Hospital, 3175 Sainte-Catherine Road, 을 Montreal, Quebec, Canada H3T 1C5. 